sought to describe morbidity and behavioural characteristics of these cases to better understand trends among this population.

Methods Data were gathered using clinic-based sentinel surveillance systems and through abstraction of Interview Records completed upon DIS interview.

Results Transgender women represented an increasing proportion of total syphilis cases identified from 2009 (3.7\% or 10/269) to 2010 (6.4\% or 20/313). The 20 cases identified in 2010 were among 19 transgender women; one client was re-infected. Of these, $2(10 \%)$ were primary, 12 $(60 \%)$ were secondary, $5(25 \%)$ were early latent, and $1(5 \%)$ was latent of unknown duration syphilis. The mean age increased slightly from 21.4 years (range 19-24) in 2009 to 24.9 years (range 19-41) in 2010. Reported race/ethnicity included: 13 (65\%) non-Hispanic black, 3 (15\%) Hispanic, 2 (10\%) non-Hispanic white, 1 (5\%) Asian/Pacific Islander and 1 (5\%) American Indian/Alaskan Native. HIV co-infection was similar to rates observed in Men who Have Sex with Men (MSM) populations (60\%); $25 \%$ of HIV-positive clients had been diagnosed in the prior year. Forty-five per cent had a history of STI (non-HIV). High rates of transient housing (30\%), unemployment $(55 \%)$, incarceration (25\%), and transactional sex $(40 \%)$ in the prior 12 months were reported. Median number of sex partners in the past year was 10 (range 0-60). No common sex partners were named during case investigation interviews during 2009 or 2010.

Conclusions Increases in syphilis among transgender women in Chicago highlight a need for enhanced screening and targeted prevention messages for this population. High levels of risk and HIV co-infection reflect potential for ongoing transmission of both HIV and other STIs.

\section{LBO-1.4 INCREASING MACROLIDE RESISTANCE IN MYCOPLASMA GENITALIUM}

doi:10.1136/sextrans-2011-050119.4

${ }^{1} \mathrm{C}$ Anagrius, ${ }^{1} \mathrm{~B}$ Loré, ${ }^{2} \mathrm{~J}$ S Jensen. ${ }^{1}$ Falu Hospital, Falun, Sweden; ${ }^{2}$ SSI, Köpenhamn, Denmark

Background To evaluate therapy outcome in $M$ genitalium infection with standard chlamydia treatment doxycyclin 9 days and azithromycin $1 \mathrm{~g}$ stat compared to extended azithromycin $15 \mathrm{~g}$ for 5 days and to evaluate macrolide resistance.

Methods Patients attending the STD-clinic in Falun, Sweden between January 1998 and December 2005 with a positive PCR test for $M$ genitalium routinely had a test of cure. Response was determined to doxycycline, azithromycin $1 \mathrm{~g}$ as a single dose and $15 \mathrm{~g}$ extended treatment primary and secondary when persistence after doxycycline. Macrolide resistance was monitored at base as well as after treatment in those testing positive after treatment with azithromycin. Macrolide resistance also was monitored yearly 2006-2010 in patients with newly detected $M$ genitalium infection. Results Totally $313 / 407$ (77\%) had a test of cure, $254 / 313$ (81\%) within 12 weeks. The eradication rate with doxycycline was $43 \%$ totally, $46 \%$ for women and 38\% for men, with azithromycin $1 \mathrm{~g}$ 92\% totally, 96\% for women and $89 \%$ for men and with azithromycin extended dosage $96 \%$ totally, $100 \%$ for women and $93 \%$ for men. Confirmed macrolide resistance developed in $7 / 7$ (100\%) of those testing positive after azithromycin $1 \mathrm{~g}$. In 2006-2007 we found no, in 2008 and 2009 1/year and in 201011 patients with macrolide resistance in newly detected $M$ genitalium.

Conclusions These findings confirms the results from other studies that doxycycline is inefficient in eradicating infection with $M$ genitalium. Although the treatment outcome with azithromycin $1 \mathrm{~g}$ was not significantly lower than with extended dosage for 5 days it was in this study associated with $100 \%$ induced macrolide resistance in those with treatment failure. A remarkable higher proportion of macrolide resistance in 2010 than earlier years was found. We will try to monitor yearly prescription of azithromycin $1 \mathrm{~g}$ in our county and all Sweden last years. Is there an increase explaining the higher proportion 2010? Azithromycine $1 \mathrm{~g}$ should be avoided as recommended therapy for $M$ genitalium as well as for chlamydia and nongonococcal urethritis. Specific diagnostics for $M$ genitalium as well as monitoring of resistance is urgent.

\section{LBO-1.5 MEN WHO HAVE SEX WITH MEN (MSM) HAVE A 140-FOLD RISK FOR HIV AND SYPHILIS COMPARED WITH OTHER MEN IN NEW YORK CITY}

doi:10.1136/sextrans-2011-050119.5

${ }^{1} \mathrm{P}$ Pathela, ${ }^{1} \mathrm{~S}$ Braunstein, ${ }^{2} \mathrm{~J}$ Schillinger, ${ }^{1} \mathrm{C}$ Shepard, ${ }^{1} \mathrm{M}$ Sweeney, ${ }^{2} \mathrm{~S}$ Blank. ${ }^{1} \mathrm{~N} Y \mathrm{C}$ Department of Health and Mental Hygiene, Queens, New York, USA; ${ }^{2}$ Centers for Disease Control and Prevention, Queens, New York, USA

Background While men who have sex with men (MSM) comprise the majority of new HIV and new syphilis cases in the U.S.,

Abstract LBO-1.5 Table 1 Annual HIV Incidence among 229 HIV-Negative Men who Have Sex with Men (MSM) Diagnosed with Rectal Chlamydia or Gonorrhoea at New York City STD Clinics Between January 2008 and December 2009

\begin{tabular}{|c|c|c|c|c|c|c|c|}
\hline & $\begin{array}{l}\text { Number of } \\
\text { patients }\end{array}$ & $\%$ & $\begin{array}{l}\text { Person-years } \\
\text { at risk }\end{array}$ & $\begin{array}{l}\text { Number of HIV } \\
\text { seroconversions by } \\
\text { STD clinic diagnoses }\end{array}$ & $\begin{array}{l}\text { Total number of HIV } \\
\text { seroconversions after } \\
\text { HIV registry cross-match }\end{array}$ & $\begin{array}{l}\text { Annual HIV } \\
\text { incidence }\end{array}$ & $95 \% \mathrm{Cl}$ \\
\hline Overall & 229 & $100 \%$ & 368.29 & 16 & 22 & 5.97 & 3.84 to 8.90 \\
\hline \multicolumn{8}{|l|}{ Age (years) } \\
\hline$<20$ & 25 & $11 \%$ & 37.07 & 4 & 4 & 10.79 & 3.42 to 26.00 \\
\hline $20-29$ & 148 & $65 \%$ & 239.90 & 9 & 13 & 5.42 & 3.01 to 9.03 \\
\hline $30-39$ & 42 & $18 \%$ & 69.56 & 2 & 5 & 7.19 & 2.63 to 15.93 \\
\hline $40+$ & 14 & $6 \%$ & 21.75 & 0 & 0 & & \\
\hline \multicolumn{8}{|l|}{ Race/ethnicity } \\
\hline Non-Hispanic White & 71 & $31 \%$ & 116.63 & 2 & 3 & 2.57 & 0.65 to 7.00 \\
\hline Non-Hispanic Black & 44 & $19 \%$ & 63.44 & 6 & 9 & 14.19 & 6.92 to 26.03 \\
\hline Hispanic & 83 & $36 \%$ & 135.40 & 5 & 5 & 3.69 & 1.35 to 8.18 \\
\hline Asian & 12 & $5 \%$ & 20.23 & 1 & 1 & 4.94 & 0.25 to 24.38 \\
\hline Other/multiple & 19 & $8 \%$ & 32.59 & 1 & 4 & 12.27 & 0.15 to 15.13 \\
\hline \multicolumn{8}{|l|}{ Rectal infection } \\
\hline Chlamydia & 158 & $69 \%$ & 252.62 & 10 & 14 & 5.54 & 3.15 to 9.08 \\
\hline Gonorrhoea & 49 & $21 \%$ & 80.85 & 4 & 5 & 6.18 & 2.27 to 13.71 \\
\hline Both & 22 & $10 \%$ & 34.82 & 1 & 3 & 8.62 & 2.19 to 23.45 \\
\hline \multicolumn{8}{|c|}{ Early syphilis concurrently or in last 2 years } \\
\hline Yes & 31 & $14 \%$ & 50.33 & 3 & 4 & 7.95 & 2.52 to 19.17 \\
\hline No & 198 & $86 \%$ & 317.96 & 12 & 18 & 5.66 & 3.46 to 8.77 \\
\hline
\end{tabular}

